OPEN ACCESS

Edited by:

Shervin Assari,

University of Michigan, USA

Reviewed by:

Sarah Rowland-Jones, John Radcliffe Hospital, UK Arezoo Shajiei,

University of Manchester, UK

*Correspondence:

Hui Xing

xingh@chinaaids.cn

'Shujia Liang, Zhiyong Shen and Jing Yan have contributed equally to this

work.

Specialty section: This article was submitted to HIV and AIDS, a section of the journal Frontiers in Public Health

Received: 19 August 2015 Accepted: 12 October 2015 Published: 27 October 2015

Citation:

Liang S, Shen Z, Yan J, Liang F, Tang Z, Liu W, Kan W, Liao L, Leng X,

Ruan Y, Xing H and Shao Y (2015)

Low virologic failure and drug

resistance among HIV-infected

patients receiving hospital-based ART

while care and outreach through

community in Guangxi, China.

Front. Public Health 3:244. doi: 10.3389/fpubh.2015.00244

\section{Low virologic failure and drug resistance among HIV-infected patients receiving hospital-based ART while care and outreach through community in Guangxi, China}

\author{
Shujia Liang ${ }^{1 \dagger}$, Zhiyong Shen ${ }^{1 \dagger}$, Jing Yan ${ }^{2,3,4+}$, Fuxiong Liang ${ }^{1}$, Zhenzhu Tang ${ }^{1}$, Wei Liu ${ }^{1}$, \\ Wei Kan ${ }^{2,3,4}$, Lingjie Liao ${ }^{2,3,4}$, Xuebing Leng ${ }^{2,3,4}$, Yuhua Ruan ${ }^{2,3,4}$, Hui Xing $^{2,3,4 *}$ and \\ Yiming Shao ${ }^{2,3,4}$ \\ ${ }^{1}$ Guangxi Center for Disease Control and Prevention, Nanning, China, ${ }^{2}$ State Key Laboratory of Infectious Disease Prevention \\ and Control, National Center for AIDS/STD Control and Prevention, Beijing, China, ${ }^{3}$ State Key Laboratory for Infectious \\ Disease Prevention and Control, Chinese Center for Disease Control and Prevention, Beijing, China, ${ }^{4}$ State Key Laboratory \\ for Infectious Disease Prevention and Control, Collaborative Innovation Center for Diagnosis and Treatment of Infectious \\ Diseases, Beijing, China
}

Objectives: To investigate human immunodeficiency virus (HIV) virologic suppression and drug resistance among HIV-infected patients receiving first-line antiretroviral treatment (ART) in hospitals while community care and outreach through local health workers in Guangxi, China.

Design: This was a series of cross-sectional surveys from 2004 to 2012 in Guangxi, supported by the Chinese National HIVDR Surveillance and Monitoring Network Working Group.

Settings: Guangxi, China.

Methods: Demographic, ART, and laboratory data (CD4+ cell count, viral load, and drug resistance) were analyzed. Factors associated with virologic suppression were identified by logistic regression analysis.

Results: A total of 780 patients were included in this study. The median treatment duration was 20.6 months (IQR 6.6-35.9). Of 780 study participants, 95.4\% of patients (744/780) had HIV virologic suppression. Among these, of the 143 patients who were infected through drug injection, only 10 (7.0\%) experienced virologic failure, and the overall prevalence of HIV drug resistance was 2.8\% (22/789). Factors associated with virologic suppression in the final multivariate models included self-reported missing doses in the past month (compared to not missing doses in the past month, $A O R=0.2$, 95\% Cl: 0.1-0.6) and initial ART regimen without 3TC (compared to initial ART regimen with $3 \mathrm{TC}, \mathrm{AOR}=0.2,95 \% \mathrm{Cl}: 0.1-0.4)$. Moreover, the trend chi-square test showed that the proportion of virologic suppression increased over time from 2004 to 2012 $(P=0.002)$. 
Conclusion: This study first demonstrated that HIV patients infected through various transmission routes can achieve an excellent treatment outcome in hospitals at or above the county level for free first-line ART in Guangxi. It is an important of ART education and adherence to intervention for achieving better treatment outcomes.

Keywords: HIV, antiretroviral treatment, virologic suppression, drug resistance, China

\section{INTRODUCTION}

Highly active antiretroviral therapy (HAART) has led to a dramatic increase in sustained suppression of human immunodeficiency virus (HIV) replication. Since HAART was developed in the early 1990s, there has been a rapid improvement in prognosis of patients infected with HIV and reduction in AIDS-related mortality $(1,2)$. In resource-rich countries, because of the use of optimal regimens and a complete monitoring system for virologic failure and drug resistance, levels of drug resistance decreased over time $(3,4)$. As a result of the scale-up of the " 3 by 5 " project in low-income and middle-income countries, an increasing number of patients received antiretroviral treatment (ART) from 2003. However, the emergence of HIV drug resistance (HIVDR) was a big challenge to the rapid development of $\operatorname{HAART}(5,6)$.

The China's National Free Antiretroviral Treatment Program (NFATP) began in 2002 and rapidly scaled-up. In 2008, China's NFATP changed the threshold of initiating free ART access to more patients (7). By the end of 2013, among the 436,817 people living with HIV in China, the total number receiving free ART had increased to 278,080 (8). In China, ART has significantly reduced mortality among HIV patients (9-11) and HIV transmission among serodiscordant couples in the Chinese national observational cohort study (12). However, meta-analysis study results showed that the pooled prevalence of HIVDR was 11.1\% during $0-12$ months and increased to $22.92 \%$ at $61-72$ months in Chinese HIV-Infected Patients Receiving First-Line HAART (13). Guangxi Zhuang Autonomous Region located on the southern coast of the China, and neighboring Vietnam in the South and Yunnan Province in the west, is the major drug trafficking route linking Guangxi with Yunnan and Vietnam. The reported cases of HIV/AIDS in Guangxi accounted for $10 \%$ of the reported numbers in China. The first HIV infection among local IDUs was observed in 1996 in Guangxi, and HIV infection through drug injection accounted for $69 \%$ of the cumulative reported cases of HIV in Guangxi in 2003 (14). However, in 2013, 93\% of reported HIV cases in Guangxi were infected through heterosexual intercourse (15). Guangxi Zhuang Autonomous Region has the highest number of reported HIV cases in China (15). Because of the capacity in county hospital-based care and management for free ART in Guangxi, the aim of this study was to evaluate virologic failure and drug resistance and associated factors among HIV-infected patients receiving first-line ART.

\section{MATERIALS AND METHODS}

\section{Study Design and Study Participants}

We conducted a series of cross-sectional surveys of HIVDR in adult patients at regional representative ART clinics in
Guangxi from 2004 to 2012. This protocol of Chinese National HIVDR Surveillance was adopted from the WHO recommended cross-sectional survey on acquired HIVDR in adult patients receiving ART, which has been described elsewhere (16-19). Firstline ART regimens before 2008 consisted of [azidothymidine (AZT) or stavudine (D4T)] + [didanosine (DDI) or lamivudine (3TC) $]+[$ nevirapine (NVP) or efavirenz (EFV)]. The second edition of the National Free ART Guideline in 2008 was revised to consist of [tenofovir (TDF) or azidothymidine $(\mathrm{AZT})]+$ lamivudine $(3 \mathrm{TC})+$ [efavirenz $(\mathrm{EFV})$ or nevirapine (NVP)] (7). The NFATP criterion for treatment was (1) CD4 cell count $<200 / \mathrm{mm}^{3}$ before 2008 , and $<350 / \mathrm{mm}^{3}$ since 2008 , (2) total lymphocyte count $<1200 / \mathrm{mm}^{3}$ before 2008 , and/or (3) WHO stage III or IV disease $(7,20)$. The study eligibility criteria were HIV patients, 18 years or older, having received first-line ART, willingness and consent to participate in the study. Patients who received second-line ART were excluded.

\section{Data Collection}

The data were collected with an interviewer-administered questionnaire. Each participant provided informed consent before participation in the study. Each subject was assigned a confidential identification number to label questionnaires and blood specimens. The questionnaire was administered by trained local staff in a private room. The questionnaire information included demographic data, HAART treatment, and self-reported adherence measures. Demographic variables included sex, ethnicity, education level, occupation, marital status, and HIV transmission route. HAART treatment variables included initial regimen, the duration of HAART, and end of HAART regimen. Selfreported adherence variables included missed ART doses in the past month. The institutional review board (IRB) of the National Center on HIV/STD Control and Prevention (NCAIDS), China CDC approved this study.

\section{Laboratory Analysis}

Blood specimens were provided by all subjects to determine $\mathrm{CD}^{+}$T-lymphocyte count (CD4 count), HIV viral load (VL), and HIVDR mutations. The CD4 count was determined by flow cytometry within $24 \mathrm{~h}$ after collection in the provincial CDC. The Plasma HIV RNA was quantified with real-time NASBA (NucliSense Easy Q, bioMerieux, France) or COBAS (Roche Applied Biosystems, Germany) according to the manufacturer recommendations. In samples with a viral load $\geq 1000$ copies $/ \mathrm{ml}$, HIVDR was determined by using an in-house polymerase chain reaction (PCR) $(16,21)$. The Stanford HIV Drug Resistance Database (http://hivdb.stanford.edu/) was used to analyze drug resistance mutation and viral subtype determination. Low-, 
intermediate-, and high-level drug resistance were defined as $\operatorname{HIVDR}(22,23)$.

\section{Data Analysis}

Questionnaire and laboratory data were double entered and compared with Epidata 3.1 (The Epidata Association Odense, Denmark), and then were analyzed by Statistical Analysis System (SAS 9.2, SAS Institute Inc., Cary, NC, USA). Demographic variables were described with descriptive statistics. Factors associated with virologic failure (viral load $\geq 1000$ copies/ml) were identified by univariate and multivariate logistic regression models. Variables with $P<0.05$ were retained in multivariate logistic regression models using stepwise selection and results were presented with adjusted odds ratio (AOR) and 95\% CIs. Hypothesis testing was two-sided with $\alpha=0.05$.

\section{RESULTS}

\section{Demographic Characteristics}

Seven hundred eighty patients were included in this study. Among these, 221 patients were investigated in 2004-2006, 114 patients were investigated in 2006-2007, and then 291 patients were surveyed in 2007-2009, whereas 154 patients were included in 2011-2012. The demographic characteristics of the subjects are shown in Table 1. Among the patients, the mean age was $39.2 \pm 12.2$ years, $61.9 \%$ were male, $87.1 \%$ belonged to the Han ethnic group, $21.9 \%$ had an education level of high school or higher, $76.9 \%$ were primarily farmers, and $23.2 \%$ were married. Reported transmission routes were $75.3 \%$ sexual transmission, $18.3 \%$ injection drug use, $1.4 \%$ blood transmission, and $5.0 \%$ other.

\section{HAART Regimens and Virologic Profiles}

Initial HAART regimens used were $\mathrm{AZT}+3 \mathrm{TC}+\mathrm{EFV}$ (12.2\%), $\quad \mathrm{AZT}+3 \mathrm{TC}+\mathrm{NVP} \quad(32.1 \%), \quad \mathrm{D} 4 \mathrm{~T}+3 \mathrm{TC}+\mathrm{EFV}$ (5.1\%), D4T + 3TC + NVP (34.7\%), and DDI-based regimens (15.9\%). The median of the duration of ART was 20.6 months. At the time of the survey, $36(4.6 \%)$ patients had a viral load $\geq 1000$ copies $/ \mathrm{ml}$. Among these subjects, 35 were successfully genotyped. CRF01_AE was the most common HIV viral subtype $(31 / 35,88.5 \%)$. Of these, 22 had detectable HIVDR mutations.

\section{HIV Drug Resistance Mutations}

Among the 35 subjects successfully genotyped with viral load $\geq 1000$ copies/ml, 22 patients were identified with HIVDR mutations, and the overall prevalence of HIVDR was 2.8\% (22/789) among HIV-infected patients receiving first-line ART. Approximately $54.5 \%(12 / 22)$ of patients were resistant to non-nucleoside reverse transcriptase inhibitor (NNRTIs) drugs, 90.9\% (20/22) of patients were resistant to nucleoside reverse transcriptase inhibitor (NRTIs) drugs, and $4.5 \%(1 / 22)$ of patients had drug resistance to protease inhibitors (PIs). In addition, $45.5 \%(10 / 22)$ of patients were identified as multi-drug resistance to NNRTIs and NRTIs. The most frequent NNRTIs mutations occurred at position 101 in the RT (reverse transcriptase) region, NRTIs mutations occurred at position 184 in the RT region, and PI
TABLE 1 | Characteristics of HIV patients receiving first-line ART in Guangxi.

\begin{tabular}{|c|c|c|}
\hline Characteristics & Number & Percentage \\
\hline $\begin{array}{l}\text { Total } \\
\text { Age (years): mean } \pm S D\end{array}$ & $\begin{array}{c}780 \\
39.2 \pm 12.2\end{array}$ & \\
\hline $\begin{array}{l}\text { Sex } \\
\text { Male } \\
\text { Female }\end{array}$ & $\begin{array}{l}483 \\
297\end{array}$ & $\begin{array}{l}61.9 \\
38.1\end{array}$ \\
\hline $\begin{array}{l}\text { Ethnicity } \\
\text { Han } \\
\text { Minorities }\end{array}$ & $\begin{array}{l}679 \\
101\end{array}$ & $\begin{array}{l}87.1 \\
12.9\end{array}$ \\
\hline $\begin{array}{l}\text { Education } \\
\text { Illiterate } \\
\text { Primary school } \\
\text { Junior high school } \\
\text { High school or more }\end{array}$ & $\begin{array}{c}33 \\
236 \\
340 \\
171\end{array}$ & $\begin{array}{c}4.2 \\
30.3 \\
43.6 \\
21.9\end{array}$ \\
\hline $\begin{array}{l}\text { Occupation } \\
\text { Others } \\
\text { Farmer }\end{array}$ & $\begin{array}{l}180 \\
600\end{array}$ & $\begin{array}{l}23.1 \\
76.9\end{array}$ \\
\hline $\begin{array}{l}\text { Married } \\
\text { Yes } \\
\text { No }\end{array}$ & $\begin{array}{l}181 \\
599\end{array}$ & $\begin{array}{l}23.2 \\
76.8\end{array}$ \\
\hline $\begin{array}{l}\text { HIV transmission route } \\
\text { Sexual intercourse } \\
\text { Drug injection } \\
\text { Blood transfusion } \\
\text { Others }\end{array}$ & $\begin{array}{c}587 \\
143 \\
11 \\
39\end{array}$ & $\begin{array}{c}75.3 \\
18.3 \\
1.4 \\
5.0\end{array}$ \\
\hline $\begin{array}{l}\text { CD4 count before ART (cells } / \mathrm{mm}^{3} \text { ) } \\
\geq 350 \\
349-200 \\
199-100 \\
<100\end{array}$ & $\begin{array}{c}10 \\
116 \\
142 \\
512\end{array}$ & $\begin{array}{c}1.3 \\
14.9 \\
18.2 \\
65.6\end{array}$ \\
\hline $\begin{array}{l}\text { Missed doses in the past month } \\
\text { No } \\
\text { Yes }\end{array}$ & $\begin{array}{c}757 \\
23\end{array}$ & $\begin{array}{c}97.9 \\
2.1\end{array}$ \\
\hline Duration of ART (months): median, IQR & 20.6 & $6.6-35.9$ \\
\hline $\begin{array}{l}\text { Initial ART regimen } \\
\text { AZT + 3TC + EFV } \\
\text { AZT + 3TC + NVP } \\
\text { D4T + 3TC + EFV } \\
\text { D4T + 3TC + NVP } \\
\text { DDI-based regimens }\end{array}$ & $\begin{array}{c}95 \\
250 \\
40 \\
271 \\
124\end{array}$ & $\begin{array}{c}12.2 \\
32.1 \\
5.1 \\
34.7 \\
15.9\end{array}$ \\
\hline
\end{tabular}

mutations occurred at position 84 in the PR (protease) region (Table 2).

\section{Predictors for HIV Virologic Suppression}

Of 780 study participants, 744 (95.4\%) had HIV virologic suppression. Univariate logistic regression models were used to examine the factors associated with HIV virologic suppression (Table 3). Ethnicity, initial ART regimen, and missed doses in the past month were associated with virologic suppression. Those found to be statistically significant were included in the multivariate logistic regression model. Factors associated with virologic suppression in the final multivariate models include self-reported missing doses in the past month (compared to not missing doses in the past month, $\mathrm{AOR}=0.2,95 \% \mathrm{CI}$ : $0.1-0.6)$ and initial ART regimen without 3TC (compared to initial ART regimen with $3 \mathrm{TC}, \mathrm{AOR}=0.2,95 \% \mathrm{CI}: 0.1-0.4)$. Moreover, the trend chi-square 
TABLE 2 | HIV drug resistance mutations among HIV patients receiving first-line ART in Guangxi.

\begin{tabular}{|c|c|c|}
\hline Antiretroviral drug & $N(\%)$ & $\begin{array}{l}\text { HIV drug resistance } \\
\text { mutations, } N(\%)\end{array}$ \\
\hline Total & $22(100.0)$ & \\
\hline $\begin{array}{l}\text { Non-nucleoside reverse } \\
\text { transcriptase inhibitors (NNRTI, any) }\end{array}$ & $12(54.5)$ & K101E/EK/H/P, 4 (18.2) \\
\hline Efavirenz $(E F V)^{a}$ & $12(54.5)$ & K103N/KN/S, 3 (13.6) \\
\hline Nevirapine (NVP) ${ }^{\mathrm{a}}$ & $12(54.5)$ & V106L/I, 2 (9.1) \\
\hline Delavirdine (DLV) & $11(50.0)$ & G190A, 2 (9.1) \\
\hline Etravirine (ETV) & $2(9.1)$ & $\begin{array}{l}\text { Y181C/I, } 2 \text { (9.1) } \\
\text { E138EQ, } 1(4.5) \\
\text { Y188L, } 1 \text { (4.5) }\end{array}$ \\
\hline $\begin{array}{l}\text { Nucleoside reverse transcriptase } \\
\text { inhibitors (NRTI, any) }\end{array}$ & $20(90.9)$ & \\
\hline Emtricitabine (FTC) & $18(81.8)$ & M184V/MV, 8 (36.4) \\
\hline Lamivudine (3TC) $)^{a}$ & $18(81.8)$ & $\mathrm{T} 69 \mathrm{I} / \mathrm{IN} / \mathrm{N}, 6$ (27.3) \\
\hline Abacavir (ABC) & $15(68.2)$ & D67DG/DN/G/N, 4 (18.2) \\
\hline Didanosine (DDI) ${ }^{a}$ & $17(77.3)$ & $\mathrm{L} 74 \mathrm{~V}, 2$ (9.1) \\
\hline Stavudine (D4T) $)^{\mathrm{a}}$ & $14(63.6)$ & M41I/LM, 2 (9.1) \\
\hline Tenofovir (TDF) ${ }^{\mathrm{a}}$ & 8 (36.4) & $\mathrm{K} 65 \mathrm{R}, 1(4.5)$ \\
\hline Azidothymidine $(A Z T)^{a}$ & $12(54.5)$ & $\begin{array}{l}\text { V75T, } 1 \text { (4.5) } \\
\text { L210M, } 1 \text { (4.5) } \\
\text { F116Y, } 1 \text { (4.5) } \\
\text { T215Y, } 1 \text { (4.5) } \\
\text { K70KR, } 1 \text { (4.5) } \\
\text { F215FIST, } 1 \text { (4.5) }\end{array}$ \\
\hline Protease inhibitors (PI, any) & $1(4.5)$ & \\
\hline Tipranavir (TPV) & $1(4.5)$ & I84IV, 1 (4.5) \\
\hline Fosamprenavir (FPV) & $1(4.5)$ & \\
\hline Lopinavir (LPV)a & $0(0.0)$ & \\
\hline Nelfinavir (NFV) & $1(4.5)$ & \\
\hline Atazanavir (ATV) & $1(4.5)$ & \\
\hline Darunavir (DRV) & $0(0.0)$ & \\
\hline Indinavir (IDV) & $1(4.5)$ & \\
\hline Saquinavir (SQV) & $1(4.5)$ & \\
\hline $\begin{array}{l}\text { Multi-drug resistance to NNRTI and } \\
\text { NRTI }\end{array}$ & $10(45.5)$ & \\
\hline
\end{tabular}

${ }^{a}$ Provided through the National Free Antiretroviral Treatment Program (NFATP).

test showed that the proportion of virologic suppression increased over time from 2004 to $2012(P=0.002)$.

\section{DISCUSSION}

In this study, we found significant low virologic failure (4.6\%) and drug resistance $(2.8 \%)$ among HIV-infected patients receiving first-line ART with the median duration of treatment of about 20month in Guangxi, China. Also, virologic suppression increased over time. A recent systematic review and meta-analysis showed that the pooled prevalence of HIVDR was $11.1 \%(95 \% \mathrm{CI}$, $7.49-16.14 \%)$, which increased to $22.92 \%$ at $61-72$ months $(95 \%$ CI, 9.45-45.86\%) among Chinese HIV-infected patients receiving first-line ART in China (13). Defining 1000 copies $/ \mathrm{ml}$ as the same threshold of virologic failure, a systematic review conducted in Sub-Saharan Africa concluded that the rate of virologic suppression were 76 and $67 \%$ with the median duration of ART at 12- and 24-month, respectively (24). Based on another systematic review conducted in resource-limited settings in 2013, HIVDR at $12-23$ months was $11.1 \%$ (25). With prolonged treatment, the rate of virologic failure and drug resistance increased over time $(26,27)$. In the $2012 \mathrm{WHO}$ drug resistance surveillance guideline, viral load suppression after 12 months of ART can be graded as poor $(<70 \%)$, fair $(70-85 \%)$, or excellent $(>85 \%)$ (28). The prevalence of virologic failure and drug resistance in our study is comparable to the virologic treatment responses seen in other developed and industrialized countries (4). What is more, of the 143 patients who were infected by drug injection, only $10(7.0 \%)$ experienced virologic failure, lower than other provinces in China and this result consist with previous study in China (19). Compared to those results, we can conclude that successful outcomes of ART can be achieved in resource-limited settings.

There are several reasons to explain low virologic failure and drug resistance among HIV-infected patients receiving first-line ART in Guangxi. First, there are three levels of AIDS hospitals providing ART for HIV patients, including provincial, prefecture, and county hospitals. One provincial hospital provides technical supports and training to each prefecture hospital, which then provides technical assistance to each county hospital. Second, although HIV patients receive treatment in hospitals at or above the county level, health staff at village clinics or township hospitals are responsible for community care and outreach, such as home visits or telephone calls for reminding of ART adherence, and making an appointment if patients did not see doctors at AIDS hospitals for ART management every 3-month follow-up. Third, all doctors and health staff for ART and care management receive comprehensive HIV/AIDS medical training. Fourth, initial ART regimen with 3TC can increase virologic suppression. Our previous studies found HIV patients who received ART at village clinics, township hospitals, or local CDCs had poor virologic outcomes, whereas treatment counseling and instruction through telephone and 3TC-based regiments were significantly associated with HIV RNA suppression (16, 29, 30).

Despite successful HIV virologic suppression in this study, patients with missed doses in the past month and initial ART regiments without $3 \mathrm{TC}$ were found to be at increased risk for poor virologic response. This indicates that measures should be continuously taken to train local medical staff, and educate patients and enhance adherence monitoring. Due to the poor outcome of patients that received DDI-based treatment, the NFATP's first-line antiretroviral regimens have been changed to exclude the use of didanosine (DDI) and to include the use of lamivudine (3TC) for all new patients beginning treatment since 2008 (7).

The prevalence of HIVDR among patients who experienced virologic failure was $62.9 \%(22 / 35)$. Of 22 patients with HIVDR, the proportions of NNRTI mutations, NRTI mutations, and PI mutations were $54.5,90.0$, and $4.5 \%$, respectively. In addition, 10 (45.5\%) were identified to be resistant to multi-drugs. M184I/V was the most common NRTI mutations and other studies in China showed similar results $(16,29)$. One PI mutation was identified in this study, because that PI was not scaled-up at that period.

The limitations can be summed up as follows. First, these results may not represent all patients in Guangxi because of the exclusion criteria and limited geographic distribution of the surveillance sites. Also, the surveys did not include all patients who have met the inclusion criteria in Guangxi, so when we draw the conclusion we should be cautious. Second, considering diverse HIV epidemic conditions in different districts in Guangxi, the difference among those districts should be considered. 
TABLE 3 | Factors associated with HIV viral suppression (viral load $<1000$ copies/ml) among HIV patients receiving first-line ART in Guangxi.

\begin{tabular}{|c|c|c|c|c|c|c|}
\hline Variable & Number & $\begin{array}{c}\text { Viral suppression } \\
\qquad N(\%)\end{array}$ & Crude OR (95\% Cl) & $P$-value & Adjusted OR (95\% Cl) & $P$-value \\
\hline & 780 & $744(95.4)$ & & & & \\
\hline \multicolumn{7}{|l|}{ Age (years) } \\
\hline$<40$ & 486 & $458(94.2)$ & & & & \\
\hline$\geq 40$ & 294 & $286(97.3)$ & $2.2(0.9,4.9)$ & 0.06 & & \\
\hline \multicolumn{7}{|l|}{ Sex } \\
\hline Male & 483 & $459(95.0)$ & & & & \\
\hline Female & 297 & $285(96.0)$ & $1.2(0.6,2.5)$ & 0.55 & & \\
\hline \multicolumn{7}{|l|}{ Ethnicity } \\
\hline Han & 679 & $652(96.0)$ & & & & \\
\hline Minorities & 101 & $92(91.1)$ & $0.4(0.2,0.9)$ & 0.03 & & \\
\hline \multicolumn{7}{|l|}{ Education } \\
\hline High school or more & 269 & $261(97.0)$ & & & & \\
\hline Junior high school or less & 511 & $483(94.5)$ & $0.5(0.2,1.8)$ & 0.12 & & \\
\hline \multicolumn{7}{|l|}{ Occupation } \\
\hline Others & 180 & $175(97.2)$ & & & & \\
\hline Farmer & 600 & $569(94.8)$ & $1.9(0.7,4.9)$ & 0.19 & & \\
\hline \multicolumn{7}{|l|}{ Married } \\
\hline No & 181 & $170(93.9)$ & & & & \\
\hline Yes & 599 & $574(95.8)$ & $1.5(0.7,3.1)$ & 0.29 & & \\
\hline \multicolumn{7}{|l|}{ CD4 cell counts before ART } \\
\hline$\geq 200$ & 126 & $123(97.6)$ & & & & \\
\hline$<200$ & 654 & $621(96.3)$ & $0.5(0.1,1.5)$ & 0.20 & & \\
\hline \multicolumn{7}{|l|}{ Initial ART regimen } \\
\hline Regimens with 3TC & 656 & $638(97.3)$ & & & & \\
\hline Regimens without 3TC & 124 & $106(85.5)$ & $0.2(0.1,0.3)$ & $<0.0001$ & $0.2(0.1,0.4)$ & $<0.0001$ \\
\hline \multicolumn{7}{|l|}{ HIV transmission route } \\
\hline Drug injection & 143 & $133(93.0)$ & & & & \\
\hline Others & 637 & $611(96.0)$ & $1.8(0.8,3.8)$ & 0.14 & & \\
\hline \multicolumn{7}{|c|}{ Missed doses in the past month } \\
\hline No & 757 & 726 (95.9) & & & & \\
\hline Yes & 23 & 18 (78.3) & $0.2(0.1,0.4)$ & $<0.001$ & $0.2(0.1,0.6)$ & 0.003 \\
\hline \multicolumn{7}{|l|}{ Time of starting ART (years) } \\
\hline Before 2006 & 182 & $165(90.7)$ & & & & \\
\hline 2006-2008 & 339 & $327(96.5)$ & $2.8(1.3,6.0)$ & 0.008 & & \\
\hline After 2008 & 259 & $252(97.3)$ & $3.7(1.5,9.1)$ & 0.004 & & \\
\hline
\end{tabular}

In summary, this study in Guangxi demonstrates that HIVinfected patients receiving first-line treatment achieve an excellent treatment outcome and we can summarize those factors associated with virologic suppression as increasing the proper use of 3TCbased regimens and strengthening the importance of adhering to treatment.

\section{CONCLUSION}

In this study, we found significant low virologic failure and drug resistance among HIV-infected patients receiving first-line ART with the median duration of treatment of about 20-month in Guangxi, China. Our study demonstrated that HIV-infected patients receiving first-line treatment can achieve an excellent treatment outcome in hospitals at or above the county level for free ART in Guangxi, and we can conclude that the increasing the proper use of 3TC-based regimens and the strengthening the importance of adhering to treatment are associated with virologic suppression.

\section{AUTHOR CONTRIBUTIONS}

JY and SL wrote the main manuscript text and FL, ZT, YS, and WL prepared Tables 1-3. WK, XL, LL, and YR collected the data. HX and YS designed the study. All authors read and approved the final manuscript.

\section{ACKNOWLEDGMENTS}

Thanks to Dr. Edward C. Mignot, Shandong University, for linguistic advice.

\section{FUNDING}

This study was supported by grants from the National Natural Science Foundation of China (81471962), Guangxi Bagui Honor Scholar, Ministry of Science and Technology of China (2012ZX10001-002), Chinese State Key Laboratory for Infectious Disease Develop Grant, and the International Development Research Center of Canada (grant \#104519-010). 


\section{REFERENCES}

1. Zhang F, Dou Z, Ma Y, Zhao Y, Liu Z, Bulterys M, et al. Five-year outcomes of the China National Free Antiretroviral Treatment Program. Ann Intern Med (2009) 151:241-51. doi:10.7326/0003-4819-151-4-20090818000006

2. Borrell C, Rodriguez-Sanz M, Pasarin MI, Brugal MT, Garcia-de-Olalla P, Mari-Dell'Olmo M, et al. AIDS mortality before and after the introduction of highly active antiretroviral therapy: does it vary with socioeconomic group in a country with a National Health System? Eur J Public Health (2006) 16:601-8. doi:10.1093/eurpub/ckl062

3. von Wyl V, Yerly S, Burgisser P, Klimkait T, Battegay M, Bernasconi E, et al. Long-term trends of HIV type 1 drug resistance prevalence among antiretroviral treatment-experienced patients in Switzerland. Clin Infect Dis (2009) 48:979-87. doi:10.1086/597352

4. De Luca A, Dunn D, Zazzi M, Camacho R, Torti C, Fanti I, et al. Declining prevalence of HIV-1 drug resistance in antiretroviral treatment-exposed individuals in Western Europe. J Infect Dis (2013) 207:1216-20. doi:10.1093/infdis/ jit017

5. Zhang F, Haberer JE, Wang Y, Zhao Y, Ma Y, Zhao D, et al. The Chinese free antiretroviral treatment program: challenges and responses. AIDS (2007) 21(Suppl 8):S143-8. doi:10.1097/01.aids.0000304710.10036.2b

6. DeGruttola V, Dix L, D'Aquila R, Holder D, Phillips A, Ait-Khaled M, et al. The relation between baseline HIV drug resistance and response to antiretroviral therapy: re-analysis of retrospective and prospective studies using a standardized data analysis plan. Antivir Ther (2000) 5:41-8.

7. Zhang FHJ, Wang Y, Wang J, Wang FS, Yun Y, Lu HY, et al. National Free HIV Antiretroviral Trseatment Handbook. 2nd ed. Beijing: People's Medical Publishing House (2008).

8. China CDC. Analysis of HIV/STD Epidemic in 2013. Beijing: Chinese Center for Disease Control and Prevention (2013).

9. Zhang F, Dou Z, Ma Y, Zhang Y, Zhao Y, Zhao D, et al. Effect of earlier initiation of antiretroviral treatment and increased treatment coverage on HIV-related mortality in China: a national observational cohort study. Lancet Infect Dis (2011) 11:516-24. doi:10.1016/S1473-3099(11)70097-4

10. Zhang F, Dou Z, Yu L, Xu J, Jiao JH, Wang N, et al. The effect of highly active antiretroviral therapy on mortality among HIV-infected former plasma donors in China. Clin Infect Dis (2008) 47:825-33. doi:10.1086/ 590945

11. Liao L, Xing H, Su B, Wang Z, Ruan Y, Wang X, et al. Impact of HIV drug resistance on virologic and immunologic failure and mortality in a cohort of patients on antiretroviral therapy in China. AIDS (2013) 27:1815-24. doi:10. 1097/QAD.0b013e3283611931

12. Jia Z, Mao Y, Zhang F, Ruan Y, Ma Y, Li J, et al. Antiretroviral therapy to prevent HIV transmission in serodiscordant couples in China (2003-11): a national observational cohort study. Lancet (2013) 382:1195-203. doi:10.1016/S01406736(12)61898-4

13. Liu H, Ma Y, Su Y, Smith MK, Liu Y, Jin Y, et al. Emerging trends of HIV drug resistance in Chinese HIV-infected patients receiving first-line highly active antiretroviral therapy: a systematic review and meta-analysis. Clin Infect Dis (2014) 59:1495-502. doi:10.1093/cid/ciu590

14. Guangxi Public Health Department. Annual Report on AIDS/STD Surveillance in 2003. Guangxi: Guangxi Public Health Department (2003).

15. NCAIDS, NCSTD, China CDC. Update on the AIDS/STD epidemic in China and main response in control and prevention in February, 2014. Chin J AIDS STD (2014) 3:145.

16. Xing H, Ruan Y, Li J, Shang H, Zhong P, Wang X, et al. HIV drug resistance and its impact on antiretroviral therapy in Chinese HIV-infected patients. PLoS One (2013) 8:e54917. doi:10.1371/journal.pone.0062408
17. Who Global Strategy for the Surveillance and Monitoring of HIV Drug Resistance (2012). Available from: http://www.who.int/hiv/pub/drugresistance/ drug_resistance_strategy/en/

18. Xing H, Ruan Y, Hsi JH, Kan W, Liao L, Leng X, et al. Reductions in virological failure and drug resistance in Chinese antiretroviral-treated patients due to lamivudine-based regimens, 2003-12. J Antimicrob Chemother (2015) 70(7):2097-103. doi:10.1093/jac/dkv078

19. Leng X, Liang S, Ma Y, Dong Y, Kan W, Goan D, et al. HIV virological failure and drug resistance among injecting drug users receiving first-line ART in China. BMJ Open (2014) 4(10):e005886. doi:10.1136/bmjopen-2014-005886

20. Zhang FHJ, Wang Y, Wang J, Wang FS, Yun Y, Lu HY, et al. National Free HIV Antiretroviral Treatment Handbook. 1nd ed. Beijing: People's Medical Publishing House (2005)

21. Wang J, He C, Hsi JH, Xu X, Liu Y, He J, et al. Virological outcomes and drug resistance in Chinese patients after 12 months of 3TC-based first-line antiretroviral treatment, 2011-2012. PLoS One (2014) 9:e88305. doi:10.1371/ journal.pone.0088305

22. Zhong $\mathrm{P}$, Pan Q, Ning Z, Xue Y, Gong J, Zhen X, et al. Genetic diversity and drug resistance of human immunodeficiency virus type 1 (HIV-1) strains circulating in Shanghai. AIDS Res Hum Retroviruses (2007) 23:847-56. doi:10.1089/aid. 2006.0196

23. Liu TF, Shafer RW. Web resources for HIV type 1 genotypic-resistance test interpretation. Clin Infect Dis (2006) 42:1608-18. doi:10.1086/503914

24. Barth RE, van der Loeff MF, Schuurman R, Hoepelman AI, Wensing AM. Virological follow-up of adult patients in antiretroviral treatment programmes in sub-Saharan Africa: a systematic review. Lancet Infect Dis (2010) 10:155-66. doi:10.1016/S1473-3099(09)70328-7

25. Stadeli KM, Richman DD. Rates of emergence of HIV drug resistance in resource-limited settings: a systematic review. Antivir Ther (2013) 18:115-23. doi:10.3851/IMP2437

26. Pennings PS. HIV drug resistance: problems and perspectives. Infect Dis Rep (2013) 5:e5. doi:10.4081/idr.2013.s1.e5

27. Ma Y, Zhao D, Yu L, Bulterys M, Robinson ML, Zhao Y, et al. Predictors of virologic failure in $\mathrm{HIV}$-1-infected adults receiving first-line antiretroviral therapy in 8 provinces in China. Clin Infect Dis (2010) 50:264-71. doi:10.1086/ 649215

28. Protocol for Population-Based Monitoring of HIVDR Emerging During Treatment And Related Program Factors at Sentinel ART Clinics (2012). Available from: http://apps.who.int/iris/bitstream/10665/75205/1/WHO_HIV_2012.15_eng. pdf

29. Wang X, Yang L, Li H, Zuo L, Liang S, Liu W, et al. Factors associated with HIV virologic failure among patients on HAART for one year at three sentinel surveillance sites in China. Curr HIV Res (2011) 9:103-11. doi:10.2174/ 157016211795569122

30. Ruan Y, Xing H, Wang X, Tang H, Wang Z, Liu H, et al. Virologic outcomes of first-line HAART and associated factors among Chinese patients with HIV in three sentinel antiretroviral treatment sites. Trop Med Int Health (2010) 15:1357-63. doi:10.1111/j.1365-3156.2010.02621.x

Conflict of Interest Statement: The authors declare that the research was conducted in the absence of any commercial or financial relationships that could be construed as a potential conflict of interest.

Copyright (C) 2015 Liang, Shen, Yan, Liang, Tang, Liu, Kan, Liao, Leng, Ruan, Xing and Shao. This is an open-access article distributed under the terms of the Creative Commons Attribution License (CC BY). The use, distribution or reproduction in other forums is permitted, provided the original author(s) or licensor are credited and that the original publication in this journal is cited, in accordance with accepted academic practice. No use, distribution or reproduction is permitted which does not comply with these terms. 